\title{
Investigating an Equitable Approach to Individualising Grades for Wiki-focused Project-based Learning in an English for Academic Purposes Context
}

\author{
Paul Kebble (Corresponding author) \\ University of Tasmania \\ Faculty of Education \\ Newnham, Tasmania, 7248, Australia \\ E-mail: paul.kebble@utas.edu.au
}

Simon Williams

Taylor's University

Subang Jaya

Malaysia

E-mail: SimonJohn.Williams@taylors.edu.my

Received: May 12, 2017 Accepted: June 1, 2017 Published: June 5, 2017

doi:10.5296/ijele.v5i2.11340 URL: https://doi.org/10.5296/ijele.v5i2.11340

\begin{abstract}
Project-based learning has enduring concerns with an individual contributor's grade allocation. An individual's final grade can be attained through whole group product assessment, individualised contribution assessment, or a combination of the two. Assessment can be achieved through external (teacher) product evaluation, internal (participant) process evaluation, or a combination of the two. If combination assessment is used, weighting of each element becomes an addressable issue. If a project utilises digital technologies, with a wiki being the predominant output format, the inherent software adds a further dimension to the assessment process. When the project is conducted by English language learners preparing for English-medium undergraduate studies, assessment becomes both linguistic and topic-focused. A limited two-cycle action research study was conducted at an English medium international university to investigate assessment methods utilising external and
\end{abstract}


internal evaluations, on which the design of an assessment framework could be based. Results from this study include a design approach to the allocation of individual grades, with an informed discussion of group assessment, including free-rider issues, co-created assessment, and score weightage.

Keywords: Assessment framework, Project-based learning, Individualised grading, Wikis, EAP

\section{Introduction}

Project-based learning (PBL) can provide excellent opportunities for learners to engage in active research-focused learning (De Wever, Van Keer, Schellens, \& Valcke, 2011; Caple \& Bogle, 2011; Exley, 2010; Poonpon, 2011). PBL employed in academic English programs has many extensively described benefits, and particularly if PBL is conducted as a group activity. For English language learners, group focused PBL also promotes the development of linguistic soft skills which facilitate group collaborations, such as those required in professional and academic communication, data collection, research etiquette, and peer negotiations. Digital technologies, including the internet, offer an environment where PBL can function inside and outside the confines of the physical institution. Utilising wikis as the platform for PBL to be situated enables individual group participants to recurrently add and monitor contributions. Through the utilisation of a wiki, each individual revision is preserved, allowing anyone involved to observe chronologic contributions, an element of functionality potentially enhancing individualised assessment. Nevertheless, through multiple implementations of group work PBL, these researchers' have experienced the process being construed negatively by some participants, particularly in relation to individual contributions and involvement, and ultimately, grade allocation. Post PBL activity student discussions have often focused on the unfair allocation of group-based grades, particularly when individual participants were construed to have contributed minimally but received the same assessment score. Based upon extensive experience, it is the belief of these researchers that the assigning of a single grade for PBL group work does not take into consideration individual contributions and is therefore unfair. From this assertion, the following described action research project has emanated, with its findings informing the development of an assessment framework through teacher/participant collusion designed to help alleviate the issues raised above.

\section{Project-based Learning (PBL), Group Work and Assessment}

The benefits of group work in student-centred, collaborative and co-operative learning have been well researched and documented (Vygotsky, 1978; Slavin, 1991; Gokhale, 1995; Slavin, 1996; Li, 2002). A review of the literature by Lai (2011) claims that collaboration in learning can have positive effects through the development of the capacity for critical thinking (Gokhale, 1995), informative retention (Johnson \& Johnson, 1986), and the opportunity to become active learners (Hew \& Cheung, 2008). For the English language learner, each of 
these elements includes a corresponding linguistic engagement and learning component set within an authentic task. More contemporarily, collaborative learning and teaching methodologies have embraced task-, project-, and problem-based learning, providing teachers with a pedagogic framework for creating effective group learning milieus. Project-based learning (PBL) requires participants to engage with a particular topic through a process of research and data collation culminating in the presentation of synthesised information through a prescribed dissemination format. PBL invariably involves pairs or groups of students working together on a pre- determined topic over a set period of time. Participant involvement with PBL can occur either in the prescribed learning area (classroom/library), externally or inevitably, both. The PBL product can be in a single or multiple modes and can include video, oral presentation, digital or paper documentation, poster, or online employing a website, blog or wiki. Participants are required to work cooperatively and collaboratively, with the expectation that each member of the group will contribute more or less equally.

The teacher's multiple roles in an English for Academic Purposes (EAP) programs employing a PBL approach are to: 1) instigate the project, 2) formulate appropriate groups, 3) provide individualised and group support and learning experiences focused on English language accuracy and contextual suitability, 4) motivate and scaffold the process, and 5) design an appropriate assessment procedure. Assessment can be achieved through the evaluation of the project's product and outcome, or an evaluation of the process, product and outcome combined. It is this researcher's belief that project-based learning design includes two fundamental learning and developmental elements, linguistic enhancement and topic engagement. The designed learning outcomes should therefore include both a linguistic and knowledge element. For example, a project might be focused on the history of a particular area, so knowledge enhancement outcomes would include demonstration of a deeper understanding of a particular geographical and social setting, the linguistic outcome would be the appropriate and accurate use of syntax required in describing an historic setting, whether orally, textually, or both. The final product would clearly demonstrate each of these learning outcome elements.

Traditionally, the teacher assumes the role of assessor and is well-positioned to objectively assign a score for the PBL product based on predetermined and disseminated criteria. This form of assessment, however, can be criticised as it ascribes an overall score purely for the product, with each group member being awarded the same score and therefore does not take into account individual performances within the PBL process. To address this criticism, individual performances within the PBL process would require assessing and evaluating. The teacher, functioning outside each group, can provide individualised summative evaluation through reflections on singular interactions when supporting learning during the PBL process. However, due to time constraints, these interactions are sporadic and invariably limited to providing linguistic support. It could be argued then, that the participants themselves are better positioned to evaluate both their and peer performances, and such evaluations, if systematised, could assist in providing a more equitable individualised final PBL score.

Within the EAP context, evaluation of linguistic accuracy and suitability is an essential requirement, and in PBL would be more appropriately achieved by the teacher. However, it is 
somewhat more difficult to formulate an individualised score through product assessment, and would require supplementary evidence such as student notebooks or PBL diaries. If the product includes an oral presentation, the teacher is well-placed to assess oral language skills, including pronunciation, and students would be encouraged to focus on the accurate pronunciation of specific project-related lexical items. A wiki-based PBL approach has the capacity to resolve many of the issue of individualising assessment.

\subsection{Wikis and $P B L$}

A wiki is a webpage that can be edited by anyone who has access to the specific online site. Each wiki edit is recorded chronologically, allowing anyone with access to view the wiki's development. Any digital commodity can be included within a wiki, allowing developers to add, insert and attach what is deemed relevant. Text can be written and edited, promoting correction, elucidation and accuracy. A wiki website will record any update each time a user signs in to the wiki website and saves updates, automatically making the data update available to the Wiki administrator via the Wiki-logs. The log feature is especially useful as it allows group members and the teacher to track who contributes what by time-stamping each moment a user logs in with their individual user I.D. (Caple and Bogle, 2011).

A PBL assignment utilising a wiki as its primary presentation platform allows individual participants to develop the project anywhere and anytime. The benefits of utilising wikis within English language learning and teaching are multiple, requiring participants to linguistically engage with research and learning materials, with the production of content, and with each other. As a teaching tool, wikis allow for individual or group support, or full class involvement. As access to the developmental progress of a PBL wiki is open to all participants, individual contributions are apparent, a fact if made clear from the outset, can promote participant involvement and informed reflective assessment of individual accomplishments. This facet of the wiki software also indicates individuals who are under-performing or involved minimally, a state that can have a detrimental impact on other group members. However, this facility also allows the teacher to focus on these individuals and provide remedial support, if required. The software design of the wiki allows for assessment both summatively, as each update can be examined, and formatively, with the final version published and presented. The former also allows an assessor to clearly analyse which group members have contributed appropriately, and those who have minimally.

\subsection{Free riders and Assessment}

Teachers implementing group work PBL in their classroom are faced with one specific challenge: how to deal with free riders (James, McInnes \& Devlin, 2002). The term 'Free riders' (Strauss \& U-Mackey, 2007) has been used to describe group work participants who contribute minimally, or decidedly less than other participants within the cooperative learning process. It is the opinion of this researcher through experiential reflection that free riding can create a feeling of resentment leading to frustration and stress for other PBL group members who perceive they are having to compensate for the lack of involvement. An assessment system that awards a single grade to the group adds to this resentment and the belief that the score does not accurately reflect the work contributed by each member (Gibbs, 2010). 
McLaughlin and Simpson (2004) discuss that by disregarding equity in the process of PBL, the collaborative learning aspect underpinning the learning theory is devalued. Commenting on the importance of assessment, Boud, Cohen \& Sampson note that: Assessment is the single most powerful influence on learning in formal courses and, if not designed well, can easily undermine the positive features of an important strategy in the repertoire of teaching and learning approaches (Boud, et al. 1999, p. 413). This researcher argues, then, that being able to identify a free-rider through a system of assessment designed to include both internal and external performance reflections, along with a mode of product presentation allowing assessment of an individual's contributions would form the basis of an equitable and rational assessment framework.

\subsection{Externally Assessing PBL Group Work}

Assessing group work as a teacher is complicated by the very nature of PBL, as projects are invariably completed over an extended period of time and often outside the physical learning and teaching environment. McLaughlin \& Simpson (2004) suggest project-based work significantly reshapes the classroom as class aims and objectives are extended over longer periods of time, and monitoring each activity and each student to maximise their contribution becomes increasingly challenging. An English teacher's role within PBL becomes somewhat non-traditional as the teacher is required to facilitate access to information, offer guidance on project direction and development, as well as provide linguistic support. External assessment, then, is informed through engagement with the final product, and can be enhanced through reflections on the teacher-participant interactions with individuals throughout the PBL process (McManus, 2008). With the final product being centred on a wiki, the external assessor is able to analyse individual linguistic contributions throughout the wiki's development by engaging with the wiki log. If the assessment includes an oral/visual presentation, other linguistic elements can also be included within the assessment process. The formulation of an assessment rubric designed specifically for the PBL assignment would be recommended, although this notion is beyond the scope of this research.

\subsection{Internally Assessing PBL Group Work}

Group work assessment may be enhanced through student reflection and evaluations as the inner workings of the project process is known only to each student within the group (Race, 2001). This suggests that such informed insights really ought to be involved in the assessment process and that in PBL a system allowing student input into the assessment process is required. A number of studies have investigated collaborative assessment (Brooks and Ammons, 2003; Hartford, 2005; Gibbs, 2010; Exley, 2010; Caple and Bogle, 2011; De Wever, 2011, Van Keer et al., 2011) utilising different methods to assess collaborative work: self-assessment, where participants reflected on their performance; group-assessment, where participants reflected upon the group's performance; and wiki history logs, where participants access the chronological history of the project development. The predominant conclusion from each of these studies is that group work participant involvement in assessment enhances collaborative learning engagement, satisfaction with the learning methodology, the assessment procedure and the final individualised result. 
Validity of internal assessment systems, however, has been discussed by Hughes (2001) and Kennedy (2006) who both question performance over- and underrating, each factor potentially providing the basis for inaccurate biased assessment. Later studies (Lejik \& Wyvill, 2001b; Wilmot \& Crawford, 2005; Sadler \& Good, 2006) found weaker learners tended to overrate their performance while stronger learners did the opposite. However, it is this researcher's summation that if all assessment factors contribute to the final result, peer assessment will counterbalance personal biased reflective assessment. Internal group assessment in wiki-based PBL can therefore be achieved through both self-assessment and peer assessment, and informed through both personal reflections and engaging with the PBL wiki's developmental history (log).

\subsection{Co-created Aassessment}

The researchers also wish to consider the notion of assessment subjectivity through hierarchy, and considered whether a teacher, in designing a system of assessment integrating both teacher and participant assessment, is still positioned hierarchically. This notion has lead the researcher to consider whether PBL group work assessment should also incorporate a form of assessment co-creation. Reynolds and Trehan (2010) deliberate on whether alternative forms of assessment (self- and/or peer) are not as inclusive as they appear, with Boud, Cohen and Sampson (1999) stating Assessment is the principle mechanism whereby staff exercise power and control over students (p. 418). The illusion of inclusivity with self-assessment lies in the notion that though the students are able to review their own performance instead of being externally assessed, they are, in fact, still being judged by an external person as the self-assessment used for judgement is designed and created externally, for them invariably by the teacher. Inclusivity may therefore not be an appropriate term as the students are still subject to what a third party, the teacher, deems to be acceptable achievement, which ultimately undermines the collaborative nature of the PBL work in which they are participants.

Williams and Lim (2015) found that how teachers believe a project should be assessed differs to how learners think a project should be assessed. Leach, Neutze and Zepke (2001) touch on this as they note that: the knowledge that teachers believe they assess, may be quite different from the knowledge learners think they present (p. 296). This prompted the researcher to establish a form of co-created assessment within this research in order to bring the learners into a truly inclusive assessment system whereby both teacher and learner have say in what constitutes quality achievement. This study then re-affirms calls by Sadler and Good (2006), Heritage (2008), McManus (2008), Maiden and Perry (2011) and Williams and Lim (2015) to involve the learners in the process of assessment development, and not simply to be recipients of it.

\subsection{Collaborated Assessment and Weightage}

To address concerns with the equitable grading of PBL group work, an assessment procedure which embraces both external (the teacher) and internal (the learners) assessment would appear to be most justifiable. This research is founded on the belief that all elements discussed previously can be incorporated into the design of an equitable EAP-PBL group 
work assessment model. However, the attainment weighting to be attributed to each assessable element in constructing the final individual participant's score must also be considered. Boud, Cohen and Sampson (1999) warn that assessment weightage to individual elements of assessment within a project can indicate to students as to its significance. For example, if the weightage attributed to a participant's involvement is relatively limited, the engagement students demonstrate may follow suit. The research focus is therefore which of these elements of assessment are most appropriate for providing an accurate individual PBL score, and what weighting each should be ascribed.

This research wishes to utilise the above discussions in the development of a robust and equitable assessment and grading scheme that can be effectively implemented for PBL projects within an academic English program. The researchers believe the most effective way to progress this research is practically and by experimentation, and believe an Action Research approach will provide the functional framework for this to be achieved. To this effect, the following questions have been formulated.

\subsection{Research Questions}

This research project wishes to elucidate on the following three questions to enable the development of a collaborative assessment framework for EAL PBL group work utilising wikis.

1. What constitutes appropriate collectable evidence to substantiate individual assessment?

2. How can individual grades be calculated appropriately and equitably?

3. Does the functionality of a wiki enhance assessment of individuals in PBL?

\section{Research Methodology}

\subsection{Action Research}

With a focus on the teacher/practitioner, an Action Research (AR) approach was designed to address the above research questions. Kemmis \& McTaggart (2005) point out that "action research involves the investigation of actual practices and not abstract practices" (p. 277). Kemmis further elucidates by stating "action research aims at changing three things: practitioners' practices, their under- standings of their practices, and the conditions in which they practise" (2009, p. 463). It is within this tenet that this research wishes to elucidate upon the 'practitioners' practice' in the equitable assessment of project-based learning activities within EAP. This research has adapted an action research framework (Figure 1) provided by Kemmis and McTaggart (2005) and informed by Kebble (2011) which utilises a two-cycle approach, whereby data is analysed and reviewed after the first intervention and further interventions designed prior to the second cycle commencement. 


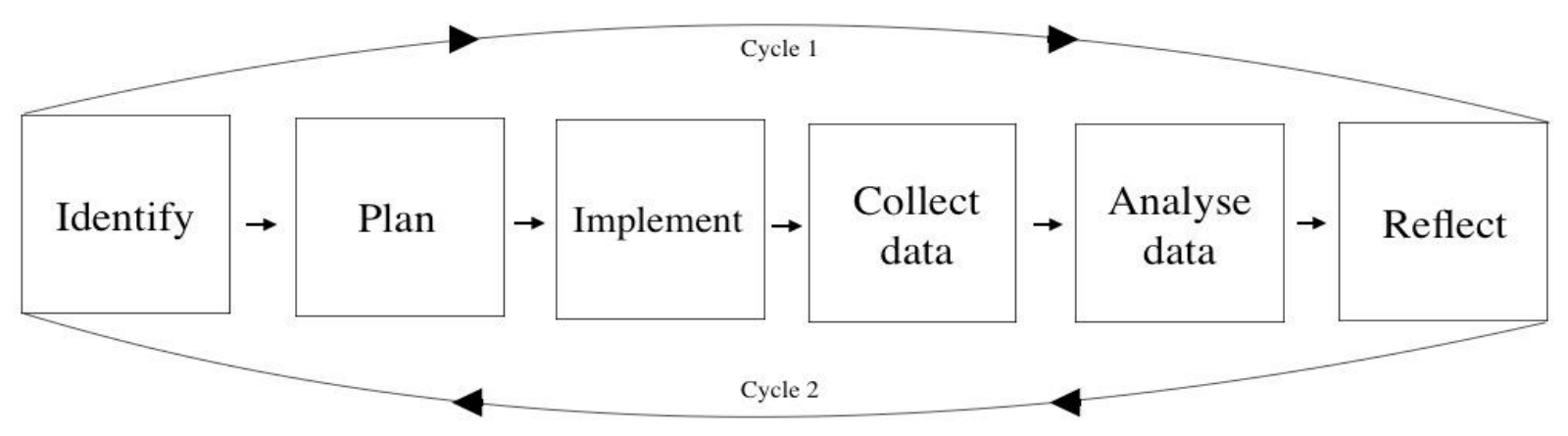

Figure 1. Adapted Action Research Framework

For this research, six stages to the action research framework have been included. Stage one asks the researcher to identify what needs to be researched. Stage two requires the researcher to plan an intervention, which is subsequently implemented in stage three. Data is collected in stage four in the form of observations, questionnaires, and live data from online tools. The data is then systematically analysed through a thematic analysis approach (Braun \& Clarke, 2006) in stage five with the final stage remaining for reflection to inform the instigation of interventions for the second cycle of the process, or from which to inform the subsequent discussion and recommendations.

\subsection{Data Collection}

Data were collected in the form of observations from the teacher/researcher, from recorded reflections on the process by individual student participants through the use of questionnaires, and from PBL whole group workings provided through the wiki log. The questionnaire was adapted from an instrument by Fisher et al. (2005), designed to gauge students' perceptions of assessment. This was given to the participants at the end of each action research cycle to ascertain their engagements with the assessment system and for the provision of feedback on the process. In addition to this data, the researchers also collated the results from self-assessments, group-evaluations and wiki logs. The teacher/researcher utilised the devised analysis of all data to inform explicated reflections upon the completion of each AR cycle (Maxwell, 2003). To critically engage with and assess these reflections, the study established a researcher/academic as a 'Critical Friend', as suggested by McNiff (2002), to provide a conduit for critical and reflective discussion, and from which to make informed inferences.

\subsection{Data Analysis}

Data collected within the action research paradigm would undergo a two-tiered thematic analysis approach where the first analysis would inform the second action research intervention, and the second analysis would inform the research's discussion and recommendations. This research utilised a simplified version of Bruan and Clarke's (2006) thematic analysis as a "method for identifying, analysing and reporting patterns within data" (p. 79). The analysis of collected data followed a 5 step approach: 1) familiarisation of data, 2) coding all data, 3) searching for themes within codes, 4) reviewing and defining themes, and 5) utilising generated themes to inform either the next action research round or final 
discussion.

\subsection{Participants}

Ten participants in total joined both cycles of the research. The participants were aged between 17 and 24 and were from Vietnam (1), Korea (2), China (3) Kazakhstan (1), Malaysia (2) and Yemen (1). Each participant identified as having English as a second or other language and had come to the university to study English before entering into the main university foundation and undergraduate degree programmes. The study was conducted during an English for academic purposes (EAP) course that was six-weeks in duration. Participants attended the course each day from $8 \mathrm{am}$ to $1 \mathrm{pm}$ and studied multiple aspects related to academic English Language learning. The PBL projects were initiated as a part of the EAP course.

\subsection{The PBL Projects}

Both PBL projects followed a framework for the formation of a constructivist learning environment (Figure 2) adapted from Jonassen (1999). Students were to complete initial research on the project, gain individualised interactional experiences with the topic focus, work with peers in the creation and production of the wiki, and share the output with others. Finally, individual participants were asked to reflect on the whole project process both as a whole class activity and individually with the teacher.

Within this research, participants were organised into groups of three to four students, and were required to complete two projects utilising a wiki framework. Participants were encouraged to operate both within the classroom, with teacher support, and externally. All group-generated information, such as meeting minutes, task lists, pictures, and designs were collated and shared on the group wikis, with the final group presentation being designed and presented within the prescribed wiki platform. The project was hosted on the wiki website 'Wikispaces' (education), with each student obliged to sign into wikispaces.com and create a personal account and user name. The projects were:

Project 1 (PBL1): Investigating and researching a country or ethnic group of which group members have had very limited prior knowledge (1 week).

Project 2 (PBL2): Redesigning, with substantiations, the EAP classroom for maximising learning, teaching and interactions, and to incorporate learning technologies (2 weeks).

\subsection{AR Cycle One}

The researchers initially identified that a categorisation of assessment correlations was required, including the naming of the inter-relations within the assessment analysis as such: 1) participant self-assessment (PSA), 2) participant peer assessment (PPA), 3) Teacher assessment of product (TAP), and 4) Teacher assessment of language (TAL). This identification would then be utilised in the designing of the assessment tools for each category. 


\section{Macrothink}

\subsubsection{PSA}

The designed assessment rubric (Figure 2) would contain six assessable topics: research, sharing, completing tasks, contribution, listening to others, and cooperation. Each topic would have three descriptors to choose from, with associated scores. Participants would be required to choose a descriptor and relevant score within that descriptor. The researchers wishes to experiment with a system that was believed to be relatively simple to utilise, but would provide scope inclusive enough to meet the needs of the task.

\begin{tabular}{|c|c|c|c|}
\hline & Very Good & Good & Developing \\
\hline $\begin{array}{c}\text { Research and } \\
\text { collecting information } \\
6\end{array}$ & $\begin{array}{l}\text { I collected lots of information from } \\
\text { various places, such as books, the } \\
\text { internet etc. } \\
6-5\end{array}$ & $\begin{array}{l}\text { I collected some information from a } \\
\text { few places. } \\
4-3\end{array}$ & $\begin{array}{l}\text { I only collected a little information } \\
\text { from few places. } \\
\qquad \begin{array}{c}2-1\end{array}\end{array}$ \\
\hline $\begin{array}{c}\text { Sharing } \\
8\end{array}$ & $\begin{array}{l}\text { I always shared my information or ideas } \\
\text { with all my team members. } \\
8-7\end{array}$ & $\begin{array}{l}\text { I sometimes shared information or } \\
\text { ideas with my team members. } \\
\qquad \begin{array}{l}6-5-4\end{array}\end{array}$ & $\begin{array}{l}\text { I shared little information or ideas } \\
\text { with my team members. } \\
\qquad \begin{array}{l}3-2-1\end{array}\end{array}$ \\
\hline$\underset{8}{\text { Completing tasks }}$ & $\begin{array}{l}\text { I met al/ deadlines and I was not late for } \\
\text { meetings or to complete work. } \\
\qquad 8-7\end{array}$ & $\begin{array}{l}\text { I met most deadlines and was only } \\
\text { late for some meetings and to } \\
\text { complete work. } \\
6-5-4\end{array}$ & $\begin{array}{l}\text { I missed many deadlines and was } \\
\text { often late for meetings or to complete } \\
\text { work. } \\
3-2-1\end{array}$ \\
\hline $\begin{array}{c}\text { Contribution } \\
8\end{array}$ & $\begin{array}{c}\text { I always helped every team member with } \\
\text { all tasks, such as gathering information, } \\
\text { editing work. } \\
8-7\end{array}$ & $\begin{array}{l}\text { I helped some of my team } \\
\text { members, but not all to gather } \\
\text { information and edit work. } \\
6\end{array}$ & $\begin{array}{l}\text { I didn't help my team mates to gather } \\
\text { information, edit work etc. } \\
\begin{array}{l}3-2-1\end{array}\end{array}$ \\
\hline $\begin{array}{l}\text { Listening to other group } \\
\text { members } \\
5\end{array}$ & $\begin{array}{l}\text { I always listened to the ideas and } \\
\text { suggestions from my team. } \\
5-4\end{array}$ & $\begin{array}{l}\text { I sometimes listened to ideas and } \\
\text { suggestions from my team. } \\
\qquad 3-2\end{array}$ & $\begin{array}{l}\text { I didn't listen to my other team } \\
\text { members. I often did it my own way. }\end{array}$ \\
\hline $\begin{array}{c}\text { Co-operating with my } \\
\text { team } \\
5\end{array}$ & $\begin{array}{l}\text { I never argued with my team members. I } \\
\text { always talked about ideas and listened } \\
\text { everyone's opinion. }\end{array}$ & $\begin{array}{l}\text { I sometimes argued with my team. } \\
\text { I sometimes talked about ideas } \\
\text { and thought about some opinions. } \\
33-2\end{array}$ & $\begin{array}{l}\text { I often argued with my team mates. I } \\
\text { never listened to their ideas and } \\
\text { didn't think about their opinions. }\end{array}$ \\
\hline
\end{tabular}

Figure 2. Participant Self-Assessment Rubric

\subsubsection{PPA}

The assessment tool (Figure 3) required the answering of four questions: (1) 'Who worked hard in your group? (2) What were their contributions?' (3) 'Who needs to work harder next time, and (4) why do you think so?' and the requirement of drawing appropriate lines onto a pie chart graphically depicting individual contributions. 


\section{Assessing your Peers}

Who worked hard in your group?

What were their contributions?

Who needs to work harder next time?

Why do you think so?

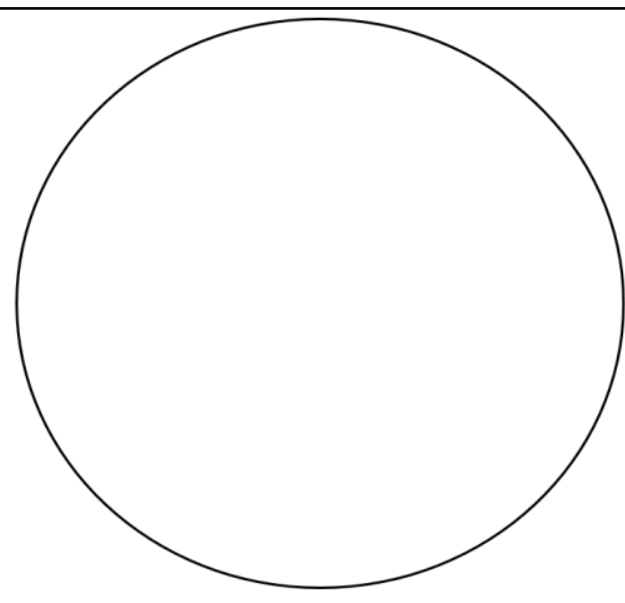

Draw lines on the pie chart to show how much each group member contributed. Write in participant's names in each piece of pie.

Figure 3. Initial Peer performance Review

In line with the discussed research on assessment over- and underrating, the use of the specific PPA form was believed to provide the researchers with corroborating data on individual contributions. Moreover, the PPA process would allow participants to voice what occurred within the group, invariably out of sight of the teacher, with the completed PPA form providing the teacher with an indication of the inner workings of the group.

\subsubsection{TAP and TAL}

The final product to be assessed solely by the teacher, where marks would be awarded for the PBL content (TAP); and linguistic structure, grammar, and vocabulary (TAL) gleaned from the completed PBL product (Figure 4).

\subsubsection{Score Weighting}

Although mindful of Reynolds and Trehan's (2010) work, the researchers decided upon a grade weightage split of $25 \%$ determined through students' responses to PPA and PSA, and $75 \%$ through teacher analysis of TAP and TAL. This decision was based upon the belief that the teacher/researcher is required to apply professional understanding and expertise to the assessment process, with the process invariably affected through professional responsibilities.

\subsubsection{Data Collection and Analysis}

The assessment results and feedback for PBL-1 were collated and coded, enabling the researchers to discover any patterns, trends or inconsistencies. Within the PPA feedback, each student was able to express their views on the inner workings of the group. For example, 
group members noted that participant 5E need (sic) to work more because she has a difficult time then. This is corroborated by participant $5 \mathrm{E}$ herself who wrote that she needed to work harder next time because she must spend more time to (sic) group work.

Contrary to the previous comments, some participants saw the group process differently from other group members. Participant 1A commented by stating that: all of us worked hard'. However, this statement was not reiterated by the remaining group members who claimed that participant 1A had (sic) absent our group meeting for two times, and sometime (sic) she forgot the deadline to finish the job. Aside from conflicting comments on contribution, some participants did indeed have their efforts recognised. Group members noted that participant $6 \mathrm{~F}$...did the most work and ... he checked the project many times.

To supplement the information provided by the PPRs, the researchers examined the Wiki logs in order to seek further confirmation of individual contribution. It was clear from the log that $6 \mathrm{~F}$ had made the most contributions to the wiki page, whereas $5 \mathrm{E}$ and $4 \mathrm{~B}$ made only a few contributions. The logs were also further corroborated by the group-evaluation where $5 \mathrm{E}$ noted that I didn't help top. Next time we need more help (sic) each other.

Through the thematic analysis of the questionnaire used to gauge students' perceptions of assessment, five themes were predominant:

a) The fairness of the $75 / 25$ split in assessment. Participants who provided feedback on this topic discussed whether this split was fair as $75 \%$ of the final individual score was still attributed to the PBL product and not to their involvement in the process. It was noted that in AR cycle one, with the PSA worth 25\% (5/20 marks) of the final grade and the teacher providing the remaining $75 \%$ (15/20 marks), that a participant received 0 from a possible 5 points for her/his PSA due to a very limited contribution. Nevertheless, the remaining group members received 12 points out of a possible 15 for their group project, plus an additional 3.5/5 points for their PSA, bringing their total score to 15.5 . Because of the $75 \%$ / $25 \%$ teacher / student split, the 'free-rider' still received a satisfactory overall score of $12 / 20$, while the participant's other team members received 15.5/20. Meaning that the free-rider was awarded a passing grade for doing very little. Participants considered if their reflections were valued more highly, and combined with evidence provided within the wiki log, this would clearly indicate involvement, which should then be more highly valued in an individualised final score.

b) The PSA review rubric was felt to be limiting in its structure and the rubric criteria was unable to provide nuances which participants wanted to discuss or raise. The attributed scoring was also criticised, particularly as there were two scores provided within each criteria.

c) Although the PPA allowed comments to be provided for other participants, the overall feeling was that this system was insufficient and limiting, especially as in some cases only two individuals were identified, limiting the capacity to assess contributions by all peers. 
d) English language assessment was based wholly upon the product, with no gauge of an individual's linguistic competence. Participants commented upon the time given by some participants on correcting other's contributions within the wiki and in the development of accurate and appropriate text.

e) Free-loading: Although there appeared to be minimal discussion of the notion of free-loading, it was still a raised issue. The researchers therefore discussed that in the second AR cycle the PSA and PPA would to be administered twice, once at the halfway point and second at the conclusion of the project. This initiative was informed through a perceived need to identify group members who might be construed as being 'free-loaders' and allow for remedial action to be instigated to support the identified learner or learners. The notion was also instigated as: 1) multiple uses of the PSA and PPA were considered to improve reliability (Ross 2006; Chang, Liang and Chen 2013), 2) administering the assessment twice allows learners to understand the importance of the specific reviewed elements in their learning; 3) teachers can assess which students might require increased support and guidance.

The data from cycle one provided the researchers with evidence that the students were effectively able to both self-assess (PSA) and comment on the contributions of other group members (PPA). However, through the subsequent discussions of the analysis of the received data, the researchers felt that the process was not as robust or encompassing as required and would be augmented through: 1) a revised PPA/PSA feedback form allowing more scope for comments, 2) two rounds of participant assessment, the first half-way through the project, the second retrospectively, 3) the researchers were able to obtained corroborating data from the Wiki logs to support assertions made by the students, a process which was considered to provide a highly valuable source of supplementary data.

The researchers also considered using wiki logs to analyse linguistic competences demonstrated through log additions and subsequent editings. It was discussed that within TAL, an individualised analysis could be conducted with a specific score attributed designed to augment the linguistic score for the overall product. Reflection on the above issues were used to identify specific areas for development and augmentation, and to plan initiative and interventions for cycle 2 of the AR process.

\subsubsection{Planning AR Cycle 2}

For AR cycle-two the following initiatives were designed for implementation and investigation:

a) The PSA and PPA to be administered jointly, with a revised and simplified form to be provided (Figure 4).

b) Two rounds of PPA/PSA would be instigated, the first halfway through and the second at the end of the PBL activity.

c) Analysis of the wiki log would be integrated into both the assessment of participant involvement and English language competencies. 
d) Assessment weightage would be 50\% from participants and 50\% from assessor.

\begin{tabular}{|c|c|c|c|}
\hline Mid-Project Re & Yoursel & nd other Group & \\
\hline Who is working & the group & d what have they & \\
\hline Who is not contr & $s$ there a re & on for this? & \\
\hline What about yout & , and is the & anything could $y$ & \\
\hline What scores out & ve yoursel & ad the other grou & \\
\hline Group Member & Score/10 & Group Member & Score/10 \\
\hline Myself: & & & \\
\hline & & & \\
\hline & & & \\
\hline
\end{tabular}

Figure 4. Revised feedback form for PSA \& PPA

\section{AR Cycle Two}

Data collected from AR cycle 2 was similarly analysed, with themes formulated through specific reference to the four initiatives informed by the AR cycle 1 . The analysis is described below.

\subsection{Initiative 1}

A Joint and simplified PSA and PPA. The data analysed within this theme focusing on the new joint form appeared to reaffirm findings by Lejik and Wyvill (2001b); Wilmot and Crawford (2005), and Sadler and Good (2006) who discussed that while some stronger students underrate performance, some weaker students may overrate. Correlation between the comments and scored provided by participants for both themselves and their peers demonstrated these findings were corroborated to a limited extent. When asked to decide who worked well, or not, in the group, participants openly indicated other members, and on some occasions stating they themselves were the ones who should work harder. The researchers considered participants might be exaggerating or underrating personal or peer performances, however, the new system of comments and scores appeared to provide a format to regulate these biases. The revised PPA/PSA format, then, appeared to initiate dual functions: 1) to provide participants with a tool to critically reflect on the contribution of themselves and their peers, and 2) to corroborate self and peer assessment scores. The teacher was able to cross check each student's PSA score with other's peer evaluation comments and scores from the PPA. The initial decision for the PPA not to be score-based was due to the researchers' 
concern that it might hinder the collaborative process, as well as raise questions over a system where learners are asked to work together only to place judgement on them upon completion of the project (Boud, Cohen and Sampson, 1999). However, reflecting on the feedback of the revised approach in AR2, the researchers were satisfied the scoring system enhanced overall objectivity and provide the teacher with valuable insights. The researchers were satisfied, through the analysis of both feedback and reflections, that this revised system was highly effective and appropriate.

\subsection{Initiative 2}

Double review system. The researchers were satisfied that administering the review system twice successfully promoted engagement and allowed participants showing limited commitment to engage more fully. It was noted that the majority of students who completed the mid-project first assessment, and were previously less involved (possible described as free-riders), were subsequently observed to be more engaged in the project. By administering the assessment process mid-project, the learners discussed feeling more informed as to assessment expectations, and the teacher was able to intervene to discover why the group process was not functioning well, and provide appropriate and timely support to individuals. No definitive conclusions can be made, but these researchers consider by completing the first round of assessment the learners realised how engagement would ultimately affect the outcome of their final grade.

\subsection{Initiative 3}

Monitoring wiki logs. Through the AR second cycle there were essentially two forms of non-direct monitoring occurring. First, as discussed above, the results from the PPA/PSA evaluation, and second, through examination of the chronological Wiki logs, the teacher could monitor group progress and individual contributions and involvement. The individual PBL group work wiki log proved to be a valuable tool for: 1) allowing the teacher to be a silent partner in the group process 2) providing evidence of individual contributions, 3) assessing language usage and linguistic competences, 4) assessing progress. As in the study described by De Wever et al. (2011), this research affirmed the effective use of the wiki logs and the wiki product. Examination of the wiki log provided a valuable data source on individual contributions, meaning the teacher was able to intervene when groups were under-achieving, when group members were not involved or contributing or give praise for those who were performing particularly well.

\subsection{Initiative 4}

Assessment Rubric and Score Weightage. For AR cycle one, the teacher implemented in a 75\% $125 \%$, teacher/student weighting for grade allocation, meaning in effect the product, assessed by the teacher, was valued three times greater than the process, assessed by the participants. In cycle-two, through review of feedback from the participants, the teacher implemented a $50 / 50$ split. With the weightage shifted to $50 \%$ process and $50 \%$ product, this appeared to rectify the previously discussed limitations and distortions. The outcome of this more equitably negotiated scoring system was highly valued by the participants and deemed fairer 
by the researchers. Feedback from participants described the fairness of the score allocation process.

\section{Concluding Discussions and Informed Recommendations}

This study wished to elucidate on three specific questions, each is answered through reflections on the research below:

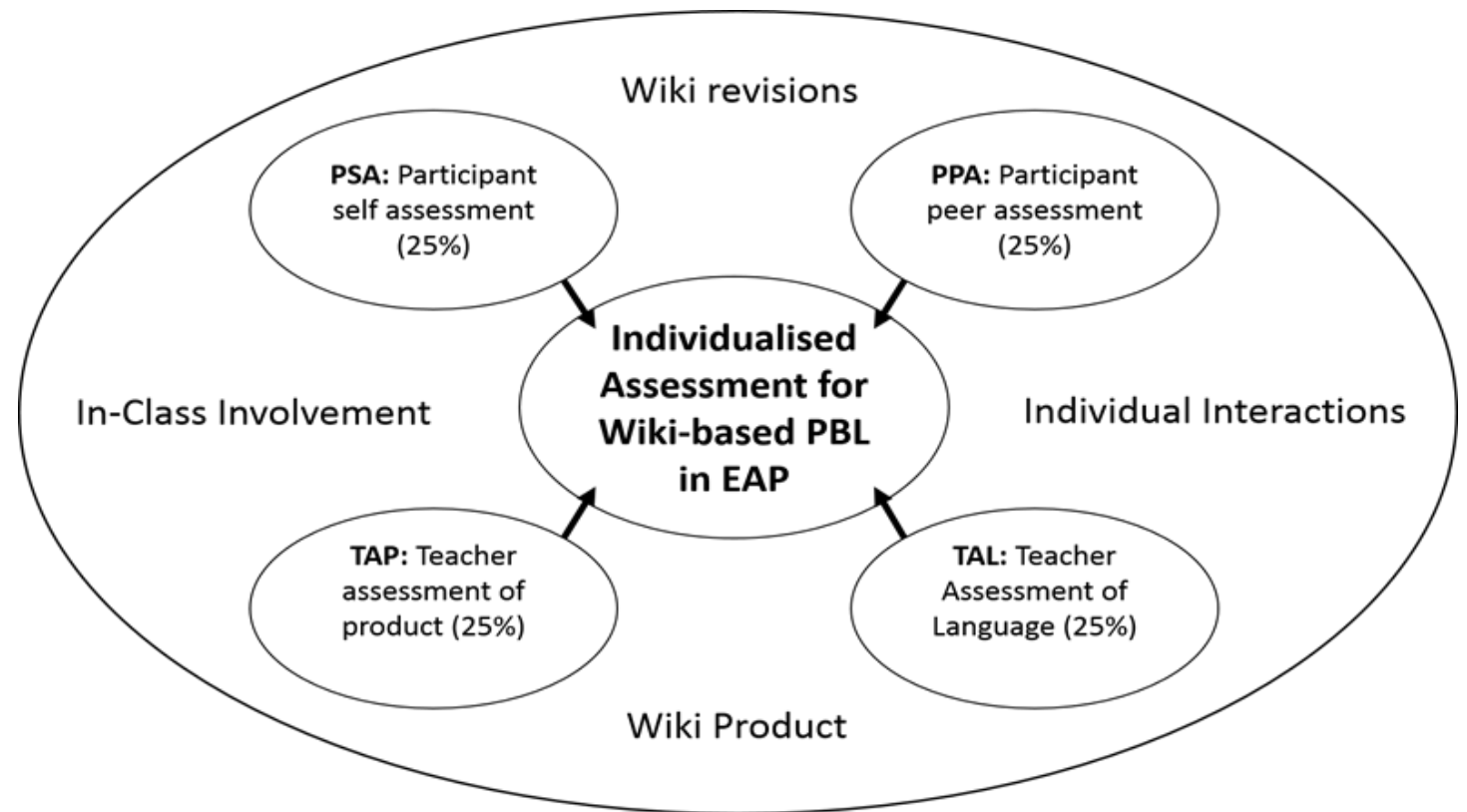

Figure 5. Collectable evidence in a wiki-based PBL assignment in EAP

First, what constitutes appropriate collectable evidence to substantiate individual assessment? This research suggests evidence for assessment can be collected from all eight elements presented within Figure 5, of which all participants in the learning and teaching process have involvement. However, participants may need to be reminded and encouraged to return to the wiki updates to provide a more objective summarisation of self and peer involvement. All data described within Figure 5 should be considered by all assessors, and scores based upon those considerations.

Question two asked how individual grades can be calculated appropriately and equitably. From this research, the equation below provides the basis for individual assessment score calculations and where each element is equally weighted:

\section{TAP score + TAL score + PSA score + Total PPA score / n-Group = Final Score}

For example, each element has a value of 10, so the maximum total possible score will be 40 . If the teacher rates TAP at 7, TAL at 6, participant's self-assessment is 7 and the average peer assessment score is 6.75 , rounded to 7 , the overall participant's score is $27 / 40$. It can be seen that within a group individual scores will vary and the system will provide a more equitable 
output.

Question three inquires whether the functionality of a wiki enhances assessment of individuals in PBL. The functionality of the wiki proved to be a highly valuable tool both in assessing the process and the product of PBL group work. The wiki log provides evidence particularly for an individual's research contribution, linguistic accuracy and overall involvement. The wiki provides a multi-literate environment for the delivery of the completed project, which in turn provides evidence for an objective overall assessment of product.

\subsection{Recommendations}

The PBL group work process is complex, requiring multiple collaborations in the production of an informed artefact. Assessing this process, and the outcome, can be more effective for participants by creating a transparent system in which all stakeholders contribute to the assessment process. This research suggests that such a strategy provides a more equitable grading process allowing learners to become more aware of, and more engaged in, performance expectations and product output. The following list provides recommendations emanating from this research and is respectfully provided for implementation and further investigation.

1) EAP - PBL group work participants should be introduced to the assessment framework at the outset of the project, to include: a) performance self-assessment (PSA), b) peer performance assessment (PPA), c) Teacher assessment rubrics for both output and language (beyond the scope of this research). The research suggests the PSA/PPA feedback form provided in Figure 5 suitably fulfils this role.

2) A final quantitative assessment of process and product should be utilised by all participants, scores informed through a reflective process to include PSAs and PPAs.

3) Equal quantitative score weightage for participant and teacher assessment should be used, with the following equation:

\section{TAP score + TAL score + PSA score + Total PPA score / n-Group = Final Score}

4) Teacher should provide qualitative feedback informed through interactions with: a) product, b) participants, c) quantitative student feedback, d) wiki log, and e) peer performance review. The mode for this feedback is also beyond the scope of this research.

5) Performance self-assessment (PSA) and Peer performance assessment (PPA) to be utilised twice through the duration of the project. The PSA/PPA form in Figure 5 can be adapted for both intermediary and final assessment.

6) All participants should engage in a Post-PBL experience discussion. 


\section{References}

Boud, D., \& Falchikov, N. (1989). The role of self-assessment in student grading. Assessment and Evaluation in Higher Education, 15(1), 101-111. http://doi.org/10.1080/0260293890140103

Boud, D., Cohen, R., \& Sampson, J. (1999). Peer learning and assessment. Assessment \& Evaluation in Higher Education, 24(4), 413-426. http://doi.org/10.1080/0260293990240405

Braun, V., \& Clarke, V. (2006). Using thematic analysis in psychology. Qualitative Research in Psychology, 3, 77-101. http://doi.org/10.1191/1478088706qp063oa

Brooks, C. M., \& Ammons, J. L. (2003). Free riding in group projects and the effects of timing, frequency and specificity of criteria in peer assessments. Journal of Education for Business, 78(5), 268-272. http://doi.org/10.1080/08832320309598613

Caple, H., \& Bogle, M. (2011). Making group assessment transparent: what wikis can contribute to collaborative projects. Assessment \& Evaluation in Higher Education, 38(2), 198-210. http://doi.org/10.1080/02602938.2011.618879

Chang, C. C., Liang, C., \& Chen, Y. H. (2013). Is learner self-assessment reliable and valid in a web-based portfolio environment for high school students? Computers \& Education, 60(1), 325-334. http://doi.org/10.1016/j.compedu.2012.05.012

De Wever, B., Van Keer, H., Schellens. T., \& Valcke, M. (2011). Assessing collaboration in a wiki: the reliability of university students' peer assessment. Internet and Higher Education, 14(4), 201-206. http://doi.org/10.1016/j.iheduc.2011.07.003

Exley, K. (2010). Managing and assessing students working in groups. Centre for Education Development. Reflections, Queen's University, Belfast.

Fisher, D. L., Waldrip, B. G., \& Dorman J. P. (2005). Student perceptions of assessment: Development and validation of a questionnaire. Paper presented at the Annual Meeting of the American Educational Research Association, Montreal, Canada, 561-568. PMid:15911875, PMCid:PMC2171702

Gibbs, G. (2010). Assessment of group work: lessons from the literature. ASKe. Retrieved from http://www.brookes.ac.uk/aske/Groupwork\%20Assessment/

Gokhale, A. A. (1995). Collaborative learning enhances critical thinking. Journal of Technology Education, 7(1). http://doi.org/10.21061/jte.v7i1.a.2

Hartford, T. (2005). Facilitation and assessment of group work using web-based tools. BEE-j, 5(1). Retrieved from http://www.heacademy.ac.uk/sites/default/files/beej.5.1f.pdf https://doi.org/10.3108/beej.2005.05000006

Heritage, M. (2008). Learning progressions: supporting instruction and formative assessment. Washington, DC: Council of Chief State School Officers (CCSSO), 1-31. Retrieved from http://www.k12.wa.us/assessment/ClassroomAssessmentIntegration/pubdocs/FASTLearning Progressions.pdf 


\section{Al Macrothink}

International Journal of English Language Education

ISSN 2325-0887

2017, Vol. 5, No. 2

Hew, K. F., \& Cheung, W. S. (2008). Attracting student participation in asynchronous online discussions: a case study of peer facilitation. Computers \& Education, 51(3), 1111-1124. http://doi.org/10.1016/j.compedu.2007.11.002

Hughes, I. E. (2001). But isn't this what you're paid for? The pros and cons of peer and self-assessment. Planet, 3(1), 20-23. http://doi.org/10.11120/plan.2001.00030020

James, R., McInnis, C., \& Devlin, M. (2002). Assessing learning in Australian universities: Centre for the Study of Higher Education (CSHE) for the Australian Universities Teaching $\begin{array}{llll}\text { Committee } & \text { (AUTC). from }\end{array}$ http://www.cshe.unimelb.edu.au/assessinglearning/03/group.html

Johnson, R. T., \& Johnson, D. W. (1986). Action Research: Cooperative learning in the science classroom. Science and Children, 24(2), 31-32.

Jonassen, D. H. (1999). Designing constructivist learning environments. In C. M. Reigeluth (Ed.), Instructional-Design Theories and Models: A New Paradigm of Instructional Theory Vol. II, 215-239, Routledge: New York, London.

Kebble, P. (2010). Electronic professional development, action research and blogging: An ideal combination. Asian EFL Journal, 45, 2.

Kemmis, S. (2009). Action research as a practice-based practice. Educational Action research, 17(3), 463-474. http://doi.org/10.1080/09650790903093284

Kemmis, S., \& R. McTaggart. (2005). Participatory Action Research: Communicative Action and the Public Sphere. Sage Publications: Thousand Oaks, CA.

Kennedy, G. J. (2005). Peer assessment in group projects: is it worth it? The Australian Computing Education Conference 2005, Newcastle, Australia, 42, 59-65.

Lai, E. R. (2011). Collaboration: A Literature Review. Retrieved from http://images.pearsonassessments.com/images/tmrs/Collaboration-Review.pdf

Leach. L., G. Neutze., \& N. Zepke. (2001). Assessment and empowerment: some critical questions. Assessment \& Evaluation in Higher Education, 26(4), 293-305. http://doi.org/10.1080/02602930120063457

Lejik, M., \& Wyvill, M. (2001). The effect of the inclusion of self-assessment with peer assessment of contributions to a group project: a quantitative study of secret and agreed assessments. Assessment and Evaluation in Higher Education, 26(6), 551-561. http://doi.org/10.1080/02602930120093887

Maiden, B., \& Perry, B. (2011). Dealing with free-riders in assessed group work: results from a study at a UK university. Assessment and Evaluation in Higher Education, 36(4), 451-464. http://doi.org/10.1080/02602930903429302

Maxwell, J. A. (2013). Qualitative Research Design (3rd Edition). Thousand Oaks, CA \& London, UK: Sage Publications. 
McLaughlin, P., \& Simpson, N. (2004). Peer assessment in first year university: how the students feel. Studies in Educational Evaluation, 30, 135-149. http://doi.org/10.1016/j.stueduc.2004.06.003

McManus, S. (2008). Attributes of effective formative assessment. Washington, DC: The Council of Chief State School Officers (CCSSO). Retrieved from www.schoolturnaroundsupport.org/resources/attributes-effective-formative

McNiff, J. (2002). Action Research for Professional Development: Concise Advice for New Action Researchers. Jean McNiff. 3. www.jeanmcniff.com/ar-booklet.asp

Poonpon, K. (2011). Enhancing English skills through project based learning. The English Teacher, Vol. XL: 1-10.

Race, P. (2001). Assessment: A briefing on self, peer and group assessment. LTSN Generic Centre Assessment Series No. 9: York LTSN Generic Centre. Retrieved from http://archive.learnhigher.ac.uk/resources/files/TTTselfpeergroup.pdf

Reynolds, M., \& Trehan, K. (2010). Assessment: A critical perspective. Studies in Higher Education, 25(3): 267-278. http://doi.org/10.1080/03075070050193406

Ross, J. A. (2006). The reliability, validity, and utility of self-assessment. Practical Assessment Research \& Evaluation, 11(10), 1-13.

Sadler, P. M., \& Good, E. (2006). The impact of self- and peer-grading on student learning. Educational Assessment, 11(1): 1-31. http://doi.org/10.1207/s15326977ea1101_1

Slavin, R. E. (1991). Student Team Learning: A Practical Guide to Cooperative Learning (Third Edition). National Education Association. Washington, DC.

Slavin, R. E. (1996). Research for the future - research on cooperative learning and achievement: What we know, what we need to know. Contemporary Educational Psychology, 21, 43-69. http://doi.org/10.1006/ceps.1996.0004

Strauss, P., \& U-Mackey, A. (2007). Group assessment: Dilemmas facing lecturers in multicultural tertiary classrooms. Higher Education Research \& Development, 26(2), 147-161. http://doi.org/10.1080/07294360701310789

Vygotsky, L. (1978). Mind In Society: The Development of Higher Psychological Processes. Cambridge: Harvard University Press.

Williams, S., \& Lim, C.H. (2015). Holistic Assessment: Creating Assessment with Students. In S. F. Tang, \& L. Logonnathan (Eds.), Taylor's 7th Teaching and Learning Conference $\begin{array}{lllll}\text { Proceedings SE } \quad-\quad 36, \quad \text { Springer } & \text { Singapore, }\end{array}$ http://doi.org/10.1007/978-981-287-399-6_36

Wilmot, P., \& Crawford, A. (2005). Validating the assessment of individuals within undergraduate teams. Proceedings of the International Conference on Engineering Education, ICEE, Gliwice. Poland, 501-506. 


\section{Copyright Disclaimer}

Copyright for this article is retained by the author(s), with first publication rights granted to the journal.

This is an open-access article distributed under the terms and conditions of the Creative Commons Attribution license (http://creativecommons.org/licenses/by/3.0/). 